\title{
PENGARUH KUALITAS PELAYANAN RECEPTIONIST TERHADAP LOYALITAS PELANGGAN DI HOTEL IBIS PADANG
}

\author{
Hani Harvisda ${ }^{1}$, Kasmita ${ }^{2}$ \\ Program Studi D4 Manajemen Perhotelan \\ Jurusan Pariwisata \\ FPP Universitas Negeri Padang \\ Email: hani.harvisda96@gmail.com
}

\begin{abstract}
This research was used to see the effect of the quality of receptionist services on customer loyalty at the Ibis Hotel Padang. This type of research is descriptive quantitative with causal associative methods. The results of this study obtained data from a sample of 99 respondents who were guests at the Ibis Hotel Padang through a questionnaire using a Likert scale, then obtained the results of a simple linear regression test obtained $F$ of 15,061 with sig. $0.000<0.05$, the receptionist service quality variable has an influence on customer loyalty variables by $13.4 \%$ and $86.6 \%$ influenced by other factors. Then obtained coefficient value of 0.369 , meaning that each increase of 1 unit of service quality of receptionist will increase 37 units of customer loyalty to guests at Ibis Hotel Padang.
\end{abstract}

\section{Keywords: Service Quality, Customer Loyalty}

\section{PENDAHULUAN}

Pariwisata di Kota Padang merupakan salah satu sektor pertumbuhan ekonomi yang diandalkan, khususnya akomodasi perhotelan.Hotel Ibis Padang merupakan salah satu hotel berbintang 3 (tiga) yang berlokasi di Jalan Taman SiswaNo.1A, Alai Parak Kopi, Padang Utara, Kota Padang, Sumatera Barat. Hotel Ibis Padang didirikan dibawah naunganAccor Asia Pasific.
Ada beberapa upaya dalam menciptakan loyalitas pelanggan dengan melihat beberapa faktor yang mempengaruhinya. Salah satu faktor tersebut yaitu kualitas pelayanan, hal ini sejalan dengan pendapat Griffin (2005: 49) yang menyatakan bahwa,

"Kualitas pelayanan menjadi salah satu hal terpenting dari beberapa aktivitas pemasaran, sebab kualitas pelayanan terdiri dari lima dimensi utama yang terdiri dari: Keandalan (Reliability), Ketanggapan Responsiveness), Jaminan 
(Assurance), Empati (Empathy), Bukti Fisik (Tangible) yang diharapkan dapat membantu organisasi untuk mencapai tujuan suatu perusahaan dalam menciptakan loyalitas pelanggan".

Berdasarkan observasi yang penulis lakukan di Hotel Ibis
Padangpada 20Mei 2018, fenomena masalah yang penulis temukan mengenai kualitas pelayanan receptionist dan loyalitas pelanggandi Hotel ini adalah fluktuatifnya jumlah penjualan kamar dalam kurun waktu 2 tahun terakhir, datanya sebagai berikut:

\begin{tabular}{|c|c|c|c|c|}
\hline \multirow[t]{2}{*}{ MONTH } & \multicolumn{4}{|c|}{ ROONS SOLD OUT } \\
\hline & $2) 16$ & $\%$ & 2017 & $\%$ \\
\hline JANZARY & 2729 & 54 & 1237 & 25 \\
\hline FEBRUARI & 3092 & 61 & 2455 & 49 \\
\hline MARCH & 3546 & 70 & 2835 & 56 \\
\hline APRIL & 3008 & 60 & 2218 & 44 \\
\hline MAI & 2122 & 42 & 1735 & 35 \\
\hline$\pi U N E$ & 2360 & 57 & 2249 & 45 \\
\hline$\pi / L$ & 2725 & 54 & 2256 & 45 \\
\hline AUGLST & 1345 & 37 & 3750 & 74 \\
\hline SEPTEMBEER & 1794 & 36 & 2124 & 42 \\
\hline$O C T C B E R$ & 3325 & 66 & 1778 & 35 \\
\hline NOVEIABER & 2115 & 42 & 3234 & 64 \\
\hline$D \overline{E C E I A B E R}$ & 3752 & 74 & 3375 & 67 \\
\hline Total & 32913 & & 29296 & \\
\hline Rata-rata & & 54 & & 48 \\
\hline
\end{tabular}

Berdasarkan tabel di atasdapat disimpulkan bahwasannya perkembangan jumlah penjualan kamar pada Hotel Ibis Padang cenderung fluktuatif, bahkan dalam 2 tahun terakhir penjualan kamar jika dirata-ratakan dalam satu tahun hanya mencapai $54 \%$ per tahun. Jika penjualan kamar tidak mencapai target akan berdampak buruk bagi hotel. Hal ini mengakibatkan berkurang nya pemasukan hotel. Hal ini mengakibatkan berkurangnya pemasukan hotel dan berakibat pada kelancaran operasional. Jika penjualan kamar sedikit tentu akan berdampak juga kepada kesejahteraan karyawan, gaji service yang di dapat hanya sedikit dan untuk menunjang biaya maintenance hotel tidak terpenuhi.

Tabel 2.Jumlah Tamu dalam 2 tahun terakhir di Ibis Hotel Padang pada Tahun 2016 - 2017

\begin{tabular}{|c|c|c|}
\hline Bulan & $\begin{array}{c}\text { Tahun } \\
\mathbf{2 0 1 6}\end{array}$ & $\begin{array}{c}\text { Tahun } \\
\mathbf{2 0 1 7}\end{array}$ \\
\hline Januari - Desember & 89.713 & 86.549 \\
\hline
\end{tabular}


Berdasarkan tabel 2 di atas dapat disimpulkan bahwasannya jumlah tamu dalam 2 tahun terakhir di Ibis Hotel Padang menurun dari tahun 2016 berjumlah 89.713 orang sedangkan pada tahun 2017 jumlah tamu sebanyak 86.549 orang.

Jumlah penjualan kamar pada suatu hotel merupakan gambaran bahwa tamu di hotel tersebut loyal, baik dari segi melakukan pembelian ulang atau menjadi pelanggan tetap, maupun dari segi merekomendasikan hotel tersebut kepada orang lain sehingga dapat menentukan sedikit atau banyaknya jumlah penjualan kamar(Azri : 2015).

Masalah selanjutnya yang berkaitan dengan kualitas pelayanan receptionist dapat dilihat pada tabel konten analisis keluhan tamu sebagai berikut:

Tabel 3.Konten Analisis Keluhan Tamu di Ibis Hotel Padang pada

\begin{tabular}{|c|l|c|c|}
\multicolumn{5}{|c|}{ Review Tripadwisor rentang waktu 2017-2018 } \\
\hline \multicolumn{1}{|c|}{ Keluhan } & Frekuensi & $\%$ \\
\hline 1 & $\begin{array}{l}\text { Tidak cekatan dalam melayani tamu sehingga } \\
\text { proses check in maupun check out menjadi lambat }\end{array}$ & 2 & 50 \\
\hline 2 & \begin{tabular}{l} 
Tidak ramah \\
\hline 3
\end{tabular} & 2 & 50 \\
\hline 4 & Tidak menjawab salam & 4 & 100 \\
\hline 5 & Kamar belum siap (ready) & 4 & 100 \\
\hline 6 & Letak hotel jauh dari fasilitas lain yang dibutuhkan & 2 & 50 \\
\hline
\end{tabular}

Sumber:Tripadyisor 2018

Berdasarkan tabel 3 di atas dapat dideskripsikan bahwasannya masih terdapat keluhan mengenai tidak cekatannya receptionist dalam melayani tamu pada saat proses check out. Kurang ramahnya receptionist dalam melayani tamu seperti yang tercemin dalam tingkah laku maupun tidak adanya salam, ucapan terima kasih maupun terima kasih kembali atas respon ketika mengucapkan terima kasih atas pelayanan mereka.
Pada saat proses check inreceptionist juga lambat dalam menangani tamu. Tamu sebelumnya sudah menginformasikan dan mengkonfirmasi ulang kepada receptionist bahwa mereka akancheck in jam 7 malam. Sesampainya di hotel, kamar belum ready dan akhirnya receptionist menginformasikan kamar yang di berikan kepada tamu adalah kamar upgrade. Setelah masuk kamar ternyata tamu mendapatkan tipe kamar yang sama dengan yang di 
booking, bukan kamar yang telah di upgrade seperti yang telah dijanjikan oleh receptionist. Hal ini membuktikan bahwa receptionist juga tidak memberikan informasi yang tepat kepada tamu.

Selanjutnya penulis juga menemukan masalah lain yang mana tamu yang telah membooking kamar melalui booking.com. Pada saat check in data bookingannya tidak ditemukan oleh receptionist, akan tetapi receptionist sebaliknya menyalahkan tamu. Seharusnya data bookingan melalui website resmi seperti booking.com telah tersimpan secara otomatis pada sistem dengan cukup mengecek pin dan password yang ditunjukkan oleh tamu.

Penulis juga menemukan
complaint tamu
receptionistyang tidak selalu siap
siaga dalam melayani tamu. Receptionist tidak menjawab telepon tamu yang sudah berdering 3 kali pada saat tamu membutuhkan amenities dengan cepat. Seharusnya receptionist cepat tanggap saat mendengar telepon tamu dan tidak mengabaikannya.

Berdasarkan masalah tersebut jika terus terjadi akan berdampak buruk bagi hotel karena tamu yang sudah memberikan ulasan pada review di website akan di baca oleh tamu yang berencana akan menginap di hotel tersebut, hal ni tentunya akan memberikan efek negatif bagi penjualan kamar di hotel tersebut karena sudah dipastikan tamu yang telah memberikan ulasan tidak akan kembali lagi ke hotel tersebut dan tidak akan merekomendasikan kepada teman, maupun keluarganya. Hal ini mengakibatkan terjadi penurunan jumlah tamu. Jika hal ini di biarkan, maka dikhawatirkan image hotel menjadi buruk dan berdampak pada perkembangan hotel.

Berdasarkan uraian fenomena masalah diatas dan mengingat pentingnya kualitas pelayanan receptionist dan loyalitas pelanggan,

Sehingga "Pengaruh Kualitas Pelayanan Receptionist Terhadap Loyalitas PelangganDi Hotel Ibis Padang" penting untuk diteliti.

\section{METODE PENELITIAN}

Penelitian ini menggunakan metode deskriptif kuantitatif dengan pendekatan assosiatif kausal. Jumlah populasi yang ditetapkan dalam penelitian ini sebanyak 7.213 orang .Jumlah sampel yang diperoleh sebanyak 99 responden.

Data primer dalam penelitian ini diperoleh langsung dari responden dengan cara menyebarkan angket diantaranya data kualitas pelayanan receptionist dan loyalitas pelanggan yang diperoleh dari sampel yang telah ditetapkan. Sedangkan data sekunder diperoleh secara tidak langsung dari objek penelitian dengan memanfaatkan data yang telah di dapat dari Hotel Ibis Padang. 
HASIL PENELITIAN DAN PEMBAHASAN

\section{Kualitas Pelayanan Receptionist}

Pernyataan

kualitas

pelayanan receptionist terdiri dari
26 butir pernyataan yang diperoleh dari indikator variabel ini sendiri. Berikut deskripsi data mengenai kualitas pelayanan receptionist, sebagai berikut:

Tabel 16. Distribusi Frekuensi Kualitas Pelayanan Receptionist $\mathrm{N}=99$

\begin{tabular}{|c|c|c|c|}
\hline Kategori & $\begin{array}{c}\text { Batas Interval Rata- } \\
\text { rata }\end{array}$ & Frekuensi & Persentase (\%) \\
\hline $\begin{array}{c}\text { Sangat } \\
\text { Setuju }\end{array}$ & $3,26-4,00$ & 0 & $0 \%$ \\
\hline Setuju & $2,51-3,25$ & 21 & $21 \%$ \\
\hline $\begin{array}{c}\text { Kurang } \\
\text { Setuju }\end{array}$ & $1,76-2,50$ & 78 & $79 \%$ \\
\hline $\begin{array}{c}\text { Tidak } \\
\text { Setuju }\end{array}$ & $1,00-1,75$ & 0 & $0 \%$ \\
\hline Total & & 99 & $100 \%$ \\
\hline
\end{tabular}

Sumber: Data Primer (Telah diolah), 2018

Merujuk pada data diatas, dapat dideskripsikan mengenai kualitas pelayanan receptionist 21 $\%$ responden berada pada kategori setuju, dan $79 \%$ berada pada kategori kurang setuju.

\section{Loyalitas Pelanggan}

Data loyalitas pelangganterdiri dari 6 butir pernyataan yang diperoleh langsung dari tamuHotel Ibis Padang dengan responden sebanyak 99 orang. Berikut adalah data loyalitas pelangganyang diperoleh dalam penelitian:

Tabel 34. Distribusi Frekuensi Loyalitas Pelanggan

\begin{tabular}{|c|c|c|c|}
\hline Kategori & $\begin{array}{l}\text { Batas Interval } \\
\text { Rata-rata }\end{array}$ & Frekuensi & $\begin{array}{l}\text { Persentase } \\
(\%)\end{array}$ \\
\hline Sangat Setuju & $3,26-4,00$ & 23 & $23 \%$ \\
\hline Setuju & $2,51-3,25$ & 30 & $30 \%$ \\
\hline Kurang Setuju & $1,76-2,50$ & 26 & $26 \%$ \\
\hline Tidak Setuju & $1,00-1,75$ & 20 & $20 \%$ \\
\hline \multicolumn{2}{|c|}{ Total } & 99 & $100 \%$ \\
\hline
\end{tabular}

Sumber: Data Primer (Telah diolah), 2018

Berdasarkan tabel tersebut mengenai deskripsi data loyalitas pelanggan, $30 \%$ pada kategori setuju $26 \%$ pada kategori kurang setuju $23 \%$ pada kategori sangat 
setuju dan $20 \%$ pada kategori tidak setuju.

\section{Analisis Data}

a. Uji

Normalitas

Tabel 42. Hasil Uji Normalitas

\begin{tabular}{|c|c|c|c|}
\hline \multicolumn{4}{|c|}{ One-Sample Kolmogorov-Smirnov Test } \\
\hline & & $\begin{array}{c}\text { Kualitas } \\
\text { Pelayanan } \\
\text { Receptionist }\end{array}$ & $\begin{array}{l}\text { Loyalitas } \\
\text { Pelanggan }\end{array}$ \\
\hline \multicolumn{2}{|l|}{$\mathrm{N}$} & 111 & 99 \\
\hline \multirow[t]{2}{*}{ Normal Parameters $^{a}$} & Mean & 61.8108 & 15.6768 \\
\hline & Std. Deviation & 4.65445 & 4.74197 \\
\hline \multirow[t]{3}{*}{ Most Extreme Differences } & Absolute & .120 & .112 \\
\hline & Positive & .056 & .108 \\
\hline & Negative & -.120 & -.112 \\
\hline \multicolumn{2}{|l|}{ Kolmogorov-Smirnov Z } & 1.262 & 1.116 \\
\hline \multicolumn{2}{|l|}{ Asymp. Sig. (2-tailed) } & .083 & .166 \\
\hline
\end{tabular}

Sumber: Data Primer (Telah diolah), 2018

Nilai significant untuk kualitas pelayanan receptionist sebesar 0.083 dan loyalitas pelanggan sebesar 0.166 dimana taraf signifikansi melebihi 0.05. Sehingga dapat dikatakan bahwa variabel $\mathrm{X}$ dan $\mathrm{Y}$ tersebut terdistribusi normal.

b. Uji

\section{Homogenitas}

Tabel 43. Hasil Uji Homogenitas

\begin{tabular}{|c|c|c|c|}
\hline $\begin{array}{r}\text { Test of } \\
\text { Loyalitas Pelangga }\end{array}$ & mogeneity & Variances & \\
\hline Levene Statistic & $\mathrm{df1}$ & df2 & Sig. \\
\hline 1.698 & 15 & 78 & .068 \\
\hline
\end{tabular}

Sumber: Data Primer (Telah diolah), 2018

Nilai signifikan yang diperoleh yaitu $0.068>0.05$. hal ini menjelaskan bahwa data berasal dari populasi yang mempunyai variance yang sama atau homogeny.

c. Uji Linearitas

Tabel 44. Hasil Uji Linearitas ANOVA Table 


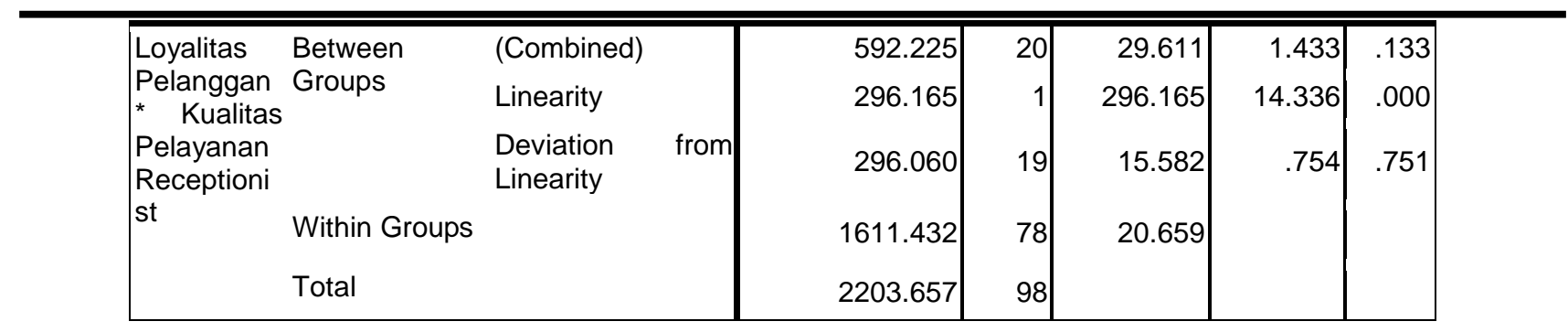

Diperoleh nilai signifikan 0.751 dimana nilai tersebut > 0.05.hal ini menunjukkan bahwa terdapat hubungan linear secara signifikan antara kualitas pelayanan receptionist terhadap loyalitas pelanggan.

\section{Pengujian Hipotesis}

Hasil analisis diperoleh nilai F sebesar 15.061 dengan taraf significant $0.000<0.05$, berarti kualitas pelayanan mempengaruhi variabel loyalitas pelangganmaka Ha diterima dan Ho ditolak yang dapat dilihat pada tabel 4 berikut:

Tabel 45. R Square Variabel X terhadap Variabel Y

\begin{tabular}{|l|r|r|r|r|}
\hline \multicolumn{5}{|c|}{ Model Summary } \\
\hline Model & R & R Square & Adjusted R Square & $\begin{array}{c}\text { Std. Error of the } \\
\text { Estimate }\end{array}$ \\
\hline 1 & .367 & .134 & .125 & 4.43451 \\
\hline a. Predictors: (Constant). Kualitas Pelayanan Receptionist \\
\hline
\end{tabular}

Sumber: Data Primer (Telah diolah), 2018

Merujuk pada data tersebut, nilai $\mathrm{R}$ Squaresebesar 0.134, artinya pengaruh variabel $\mathrm{X}$ terhadap variabel $\mathrm{Y}$ adalah sebesar $13,4 \%$. Sedangkan $86,6 \%$ dipengaruhi oleh faktor lain.

Tabel 46. Hasil Uji Regresi Linear Sederhana

\begin{tabular}{|l|r|r|r|r|r|}
\hline \multicolumn{7}{|c|}{ ANOVA $^{\text {D }}$} \\
\hline Model & Sum of Squares & df & Mean Square & F & Sig. \\
\hline 1 Regression & 296.165 & 1 & 296.165 & 15.061 & $.000^{\mathrm{a}}$ \\
Residual & 1907.492 & 97 & 19.665 & & \\
Total & 2203.657 & 98 & & & \\
\hline a. Predictors: (Constant), Kualitas Pelayanan Receptionist & & \\
b. Dependent Variable: Loyalitas Pelanggan & & \\
\hline
\end{tabular}

Sumber: Data Primer (Telah diolah), 2018 
Berdasarkan tabel diatas, hasil uji regresi linear sederhana diperoleh nilai $\mathrm{F}$ sebesar 15.061 dengan taraf signifikansi sebesar $0.00<0.05$, artinya variabel $\begin{array}{lr}\text { kualitas pelayanan } & \text { receptionist } \\ \text { mempengaruhi } & \text { loyalitas }\end{array}$ pelanggan, maka Ha diterima dan Ho ditolak.

Tabel 47. Koefisien Regresi Variabel X terhadap Variabel Y

\begin{tabular}{|c|c|c|c|c|c|}
\hline \multicolumn{6}{|c|}{ Coefficients $^{\mathrm{a}}$} \\
\hline \multirow[b]{2}{*}{ Model } & \multicolumn{2}{|c|}{$\begin{array}{c}\text { Unstandardized } \\
\text { Coefficients }\end{array}$} & \multirow{2}{*}{\begin{tabular}{|c|}
$\begin{array}{c}\text { Standardized } \\
\text { Coefficients }\end{array}$ \\
Beta \\
\end{tabular}} & \multirow[b]{2}{*}{$\mathrm{t}$} & \multirow[b]{2}{*}{ Sig. } \\
\hline & B & Std. Error & & & \\
\hline$-($ Constant $)$ & 7.056 & 5.875 & & 1.201 & .233 \\
\hline $\begin{array}{l}\text { Kualitas Pelayanan } \\
\text { Receptionist }\end{array}$ & .369 & .095 & .367 & 3.881 & .000 \\
\hline
\end{tabular}

Sumber: Data Primer (Telah diolah), 2018

Berdasarkan tabel diatas, diperoleh nilai $\mathrm{t}$ sebesar 3.881 dengan taraf signifikansi $0.00<0.05$, artinya variabel $\mathrm{X}$ menjelaskan variabel $Y$ secara signifikan. Selanjutnya untuk mengetahui besar koefisien regresi antara variabel kualitas pelayanan receptionist (X) terhadap loyalitas pelanggan (Y).

Selanjutnya diperoleh nilai $\mathrm{t}$ sebesar 3.881 dengan taraf significant $0.000<0.05$, artinya variabel kualitas pelayanan receptionist menjelaskan variabel loyalitas pelanggan secara significant. Kemudian diperoleh koefisien regresi sebesar 0.369 dengan nilai sig. $0.000<0.05$. Artinya setiap peningkatan sebesar 1 satuan kualitas pelayanan receptionist akan meningkatkan 37 satuan loyalitas pelanggandi Hotel Ibis Padang.

\section{Pembahasan}

\section{a. Kualitas Pelayanan Receptionist} Berdasarkan hasil pengkategorian skor dan rata-rata variabel kualitas pelayanan receptionist di Hotel Ibis Padang diperoleh hasil distribusi frekuensi kualitas pelayanan receptionist sebesar 79 responden berada pada interval $1,76-2,50$ dengan kategori kurang baik dan hasil rekapitulasi tanggapan responden berdasarkan 26 item pernyataan tentang kualitas pelayanan receptionist yang ditujukan diperoleh rata-rata total skor 3,2 pada batas interval 2,51 3,25 dengan kategori baik. Menurut Lewis dan Booms dalam Tjiptono Chandra (2011), "Kualitas pelayanan sebagai ukuran seberapa baik tingkat layanan yang diberikan sesuai 
dengan harapan tamu". Karena responden membutuhkan akomodasi di Padang dengan kualitas pelayanan receptionist yang dapat disimpulkan bahwa kualitas pelayanan receptionist di Hotel Ibis Padang dikategorikan secara keseluruhan baik.

$\begin{array}{lrr}\text { Hasil analisis } & \begin{array}{r}\text { deskriptif } \\ \text { semua indikator } \\ \text { pelayanan }\end{array} \\ \text { receptionist }\end{array}$
dikategorikan baik. Hal ini menggambarkan bahwa Hotel Ibis Padang telah memberikan pelayanan yang baik kepada tamu. Hal ini sejalan dengan pendapat Kotler (2009:83) bahwa, "Kualitas pelayanan merupakan suatu hal yang penting untuk diperhatikan oleh suatu usaha perhotelan, karena perhotelan merupakan salah satu usaha jasa pelayanan yang tidak mudah pengelolaannya dalam memberikan fasilitas dan pelayanan bagi tamu-tamunya".

\section{b. Loyalitas Pelanggan}

Berdasarkan

hasil

pengkategorian skor dan rata-rata variabel loyalitas pelanggan di Hotel Ibis Padang diperoleh hasil distribusi frekuensi loyalitas pelanggan sebesar $30 \quad \%$ responden berada pada interval 2,51 - 3,25 dengan kategori baik dan hasil rekapitulasi tanggapan responden berdasarkan 6 item pernyataan tentang loyalitas pelanggan yang diajukan diperoleh rata-rata total skor 2,5 pada batas interval 2,51 - 3,25 dengan kategori baik. Menurut Hurriyatti (2005:129), “Loyalitas pelanggan adalah komitemen pelanggan bertahan secara mendalam untuk berlangganan kembali atau melakukan pembelian ulang produk/jasa terpilih secara konsisten di masa yang akan datang, meskipun pengaruh situasi dan usaha-usaha pemasaran mempunyai potensi untuk menyebabkan perubahan perilaku. Dapat disimpulkan bahwa loyalitas pelanggan di Hotel Ibis Padang dikategorikan secara keseluruhan baik. Karena loyalitas pelanggan memiliki peran penting dalam sebuah perusahaan, mempertahankan mereka berarti meningkatkan kinerja keuangan dan mempertahankan kelangsungan hidup perusahaan, hal ini menjadi alasan utama bagi perusahaan untuk menarik dan mempertahankan mereka.

Hasil analisis deskriptif variabel loyalitas pelanggan semua indikator tergolong setuju. Menurut pendapat Berry dalam Tijptono (2005). (Dalam Rofiq, 2009) menyatakan loyalitas pelanggan (customer loyalty) dapat didefenisikan sebagai respon yang terkait erat dengan ikrar atau janji untuk memegang teguh komitmen yang mendasari 


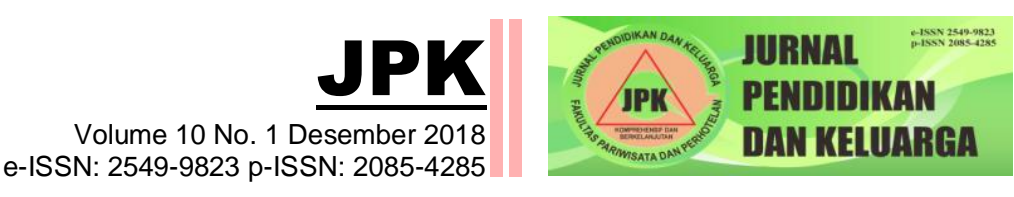

keberlanjutan relasi, dan biasanya tercermin dalam pembelian ulang yang konsisten".

\section{c. Pengaruh Kualitas Pelayanan Receptionist Terhadap Loyalitas Pelanggan di Hotel Ibis Padang}

Berdasarkan hasil pengujian hipotesis yang telah dilakukan guna untuk mengetahui tentang pengaruh kualitas pelayanan receptionist di Hotel Ibis Padang yang dianalisis menggunakan SPSS versi 16.00 diperoleh hasil uji regresi linear sederhana diperoleh $\mathrm{F} 15.061$ dengan taraf signifikan $0,000<0,05$ dan nilai $\mathrm{t}$ 3.881 dengan nilai signifikan $0,000<0,05$ sehingga dapat disimpulkan bahwa kualitas pelayanan receptionist mempunyai pengaruh yang signifikan terhadap loyalitas pelanggan, maka Ha diterima dan Ho ditolak.

Nilai koefisien regresi sebesar 0,369 dengan nilai signifikan $0,000<0,05$ yang berarti disetiap peningkatan sebesar 1 satuan kualitas pelayanan receptionist akan meningkatkan $0,37 \quad$ satuan loyalitas pelanggan dan nilai $R$ Square sebesar 0,134 yang berarti pengaruh variabel $\mathrm{X}$ (kualitas pelayanan receptionist) terhadap variabel Y (loyalitas pelanggan) adalah sebesar $0,134 \quad(13,4 \%)$ sedangkan $\quad 86,6 \quad \% \quad$ lainnya dipengaruhi oleh faktor lain.

\section{KESIMPULAN DAN SARAN}

\section{Kesimpulan}

$$
\text { Kualitas Pelayanan }
$$

Receptionist terhadap Loyalitas

Pelanggan Hotel Ibis Padang menunjukkan secara keseluruhan penilaian kualitas pelayanan receptionist termasuk dalam kategori baik pada batas interval 2,51 - 3,25 dengan rata-rata total skor sebesar 2,6 . Kemudian loyalitas pelanggan termasuk dalam kategori tidak baik pada batas interval 1,00 1,75dengan rata-rata total skor sebesar 1,0 Selanjutnya pengaruh significant antara kualitas pelayanan receptionist terhadap loyalitas pelanggan di Hotel Ibis Padang sebesar $\quad 13.4 \%$ dan $86.6 \%$ dipengaruhi oleh faktor lain seperti harga, biaya,faktor emosional, kualitas produk, dan lain sebagainya.

\section{Saran}

Kepada manajemen hotel agar selalu memperhatikan kualitas pelayanan receptionist di Hotel Ibis Padang harus lebih ditingkatkan lagi, agar tidak adanya pelanggan yang merasa kurang puas terhadap pelayanan hotel, misalnya memberikan pelatihan bagi receptionist yang dirasa bermasalah dalam menangani tamu, menjalankan sesuai dengan Standard Operating Procedures (SOP) yang telah ditetapkan, serta selalu briefing sebelum memulai pekerjaan. 


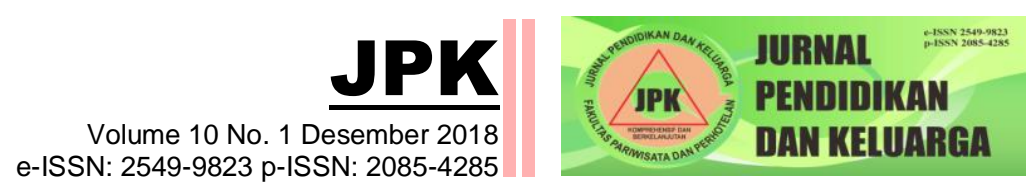

Agar loyalitas pelanggan

semakin meningkat, maka pihak hotel perlu memperhatikan apa yang dibutuhkan oleh pelanggan, misalnya seperti meningkatkan kemampuan dan disiplin karyawan dan staff dengan menerapkan konsep pengembangan sumber daya manusia yang terpadu dalam membangun etos kerja serta meningkatkan mutu pelayanan dan team work agar terwujudnya pelayanan yang berkualitas.

\section{DAFTAR PUSTAKA}

Griffin, Jill. 2005. Customer Loyalty, Menumbuhkan dan

Mempertahankan Kesetiaan

Pelanggan. Diterjemahkan oleh Dwi Kartini Yahya, Jakarta: Erlangga.

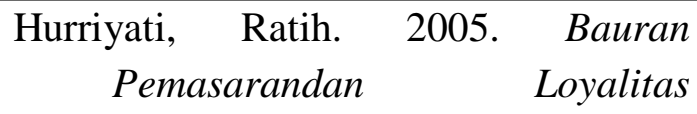
Konsumen. Bandung: Alfabeta.

Kotler dan Ketler. 2009. Manajemen Pemasaran. Jilid 1. Jakarta: Erlangga.

Rofiq,Ainur. 2009. Peranan Ekuitas Merek Terhadap Loyalitas Pelanggan Pada Industri Telepon Seluler. Bandung: Universitas Brawijaya Malang (https://www.neliti.com/, diakses pada 1 Juli 2018)

Tjiptono, Fandi. 2005. Pemasaran Jasa. Banyumedia Publishing: Malang.

Tjiptono, Fandi dan Chandra, G. 2011. Service, Quality \& Satisfaction (edisi

ketiga). Yogyakarta: Andi. 